\title{
Evaluation of eating and rumination behaviour using a noseband pressure sensor in cows during the peripartum period
}

\author{
Ueli Braun*, Theresa Tschoner and Michael Hässig
}

\begin{abstract}
Background: Eating and rumination variables were recorded in ten healthy cows over 5 days (group A) to generate reference intervals for comparison with the same variables recorded in ten cows in advanced pregnancy from ten days prepartum to ten days postpartum (group B). A pressure sensor integrated into the noseband of a halter recorded individual chewing movements. The endpoints calculated on a daily basis for each cow included duration of eating and rumination, number of eating and rumination phases, number of chewing cycles during eating and rumination, number of regurgitated cuds and number of chewing cycles per cud.

Results: The following reference intervals were established in the cows of group A: duration of eating, 212 to 394 min; number of chewing cycles during eating $13^{\prime} 101$ to 26'515; number of eating phases 10 to 24; duration of rumination 304 to $471 \mathrm{~min}$; number of regurgitated cuds 366 to 611; number of chewing cycles per cud 53 to 57; and number of rumination phases 9 to 18. In the cows of group B, duration of eating was 186 min and below the normal range ten days prepartum and decreased to 114 min on the day of calving, after which time it increased significantly to 266 min by day 10 . The number of chewing cycles during eating had the same profile as duration of eating. Duration of rumination was in the normal range except for the day of parturition. It varied from 329 to $391 \mathrm{~min}$ prepartum, decreased significantly to $214 \mathrm{~min}$ on the day of parturition and then more than doubled by day 10. The number of regurgitated cuds had a profile similar to the duration of rumination. The number of chewing cycles per cud was lowest on the day before and the day of parturition and ranged from 45 to 61 .

Conclusions: This study showed that eating and rumination variables decrease from ten days before parturition to a minimum on the day of parturition, after which time they increase.
\end{abstract}

Keywords: Cattle, Eating, Rumination, Parturition, Prepartum, Postpartum

\section{Background}

The eating and rumination behaviour of dairy cows provides valuable insight into their general health and has been the subject of numerous studies [1-7]. The peripartum period is particularly important because this is when certain disorders such as parturient paresis, retention of placenta, ketosis and left displacement of the abomasum often occur. Identifying abnormal eating and rumination behaviour during the peripartum period may aid in detecting cows with subclinical disease, thereby allowing prompt treatment. It is therefore essential to

\footnotetext{
* Correspondence: ubraun@vetclinics.uzh.ch

Department of Farm Animals, Vetsuisse-Faculty, University of Zurich, Winterthurerstrasse 260, CH-8057 Zurich, Switzerland
}

establish reference values for eating and rumination in healthy cows in the peripartum period. Studies have shown that eating and rumination behaviour are altered toward the end of the ninth month of pregnancy primarily because the gravid uterus reduces the space available for ruminal expansion by one third $[8,9]$. Based on studies in sheep [10], increased levels of estrogen near the end of pregnancy may reduce feed intake. In one study, feed intake decreased in cows during the last six weeks of pregnancy and was lowest the day of parturition [8]. It was shown that feed intake in pregnant cows decreased by 35 percent two weeks before parturition, after which time it increased by 99 percent in the first three weeks postpartum [11]. Another study reported that feed intake decreased ten days before parturition and then 
increased two to three days after calving in cows [12]. An early study compared the feeding behaviour of open cows and cows in advanced pregnancy (38.2 \pm 11.03 days prepartum) using monozygous twins [13]. The pregnant cows ate less hay and considerably more slowly than the non-pregnant cows, and the duration of eating and rumination was therefore longer in the pregnant cows. Another study determined that rumination decreased significantly as pregnancy progressed; rumination lasted 450 minutes per day in the 7th and 8th months of pregnancy, but decreased to 429 minutes per day in the 9th month [14]. Monitoring cows during the transition period using the Hi-Tag electronic rumination monitoring system revealed that rumination was shortest at the time of parturition [15]. In addition to eating and rumination times, more recent studies using automated techniques have determined the number of chewing cycles during eating and rumination as well as the number of regurgitated cuds and the number of chewing cycles per cud in cows [16]. In the past, determination of these data was only possible through time-consuming observation of individual animals. The objective of the present study was to determine the eating and rumination variables in ten pregnant cows from ten days before to ten days after parturition and to compare the results with those of non pregnant cows.

\section{Methods}

\section{Animals}

The study was carried out in the winter feeding period from November 23, 2012 to April 21, 2013. Group A (control group) consisted of ten healthy Swiss Braunvieh cows aged 3.2 to 5.5 years (mean $\pm \mathrm{sd}=4.4 \pm 0.9$ years). The cows were 32 to 202 days postpartum (112.6 \pm 62.1 days), and milk production ranged from 21.5 to $38.3 \mathrm{~kg}$ per day $(28.0 \pm 6.1 \mathrm{~kg})$. The cows were housed in tie-stalls, had free access to water and were fed hay ad libitum. In addition, they received $2 \mathrm{~kg}$ of shredded sugar beet pulp and $2.5 \mathrm{~kg}$ of concentrate (UFA 277 dairy concentrate, UFA AG, Lenzburg) twice daily. Eating and rumination activities were recorded over a fiveday period (120 hours).

Group B (cows in peripartum period) consisted of seven Swiss Braunvieh and three Swiss Fleckvieh cows aged 3.6 to 14.3 years $(7.3 \pm 3.4$ years $)$. All of the cows were in advanced pregnancy and were housed in tiestalls with free access to water and hay. Calving took place from January to March in group B. After calving, the cows received corn silage and shredded sugar beet pulp twice daily. Recording of eating and rumination variables started 20 days before the calculated due date and ended ten days after parturition. The day of parturition was defined as day 0 . Only the values recorded from ten days before to ten days after calving were used for analysis.

\section{Clinical examination}

All of the cows underwent clinical examination using the method described [17] to ensure that they were healthy. This included assessment of general condition and demeanour, rectal temperature, the heart and circulatory system, the respiratory system and the digestive tract. A urine dipstick test (Combur-9-Test ${ }^{\oplus}$, Roche Pharma AG, Grenzach, Germany) and a glutaraldehyde test (Glutaltest ${ }^{\oplus}$, Graeub AG, Bern), both of which yielded normal results, were carried out as well.

\section{Pressure transducer recordings of eating and rumination activities}

The recordings were made as described recently $[7,16]$ using a pressure sensor integrated into the noseband of a horse halter (MSR Electronics, Seuzach, Switzerland). Jaw movements were picked up by the sensor. Opening of the mouth caused bending of a tube, resulting in an increase in pressure within the tube. The sensor was connected to a data logger (MSR 145 W, MSR Electronics), which was kept in a leather pouch on the side of the halter and contained a secure digital (SD) card to store the physical measurements. The SD card had a 4 GB capacity, which allowed a measuring period of three weeks. At the end of a measuring period, the data were uploaded from the logger to a personal computer using the SD card.

\section{Analysis of pressure transducer recordings}

A special software program (R V2.12.1, MSR Electronics) was used to evaluate the data. Eating and rumination could be easily differentiated based on their characteristic pressure profiles. So-called learning files were created for each cow to aid in automating the analysis. A learning file comprised ten-minute sequences of each activity in which rumination and eating were readily identifiable. A so-called classifier (random forest) was then calibrated by means of the learning files and was used to identify eating and rumination activities in the recordings. A chewing cycle was identified by a peak in the pressure recording. For the evaluation of eating and rumination activity, chewing cycles in close succession were combined into blocks (eating phases, rumination phases, rumination activity per cud). The analysis of the learning files involved the following: identification of chewing cycles and blocks, calculation of the variables used for classification, training of the classifier, classification of chewing cycles, assignment of chewing cycles of a block to the respective activity, analysis and graphical representation of the pressure recordings using a software program (Viewer2 V1.00.03, MSR Electronics). The endpoints for each cow were calculated on a daily basis and included duration and number of eating and rumination phases, number of chewing cycles during eating and 
rumination, number of regurgitated cuds and number of chewing cycles per cud.

\section{Calculation of reference intervals}

The values generated by the control group (group A) were used to establish reference intervals. The mean, standard deviation (sd) and median of each variable were calculated from the data collected during five days. For variables with normal distribution, the reference interval was defined as the mean $\pm 2 \mathrm{sd}$, and for variables with non-normal distribution, it was defined as the $90 \%$ confidence interval of the median.

\section{Statistical analysis}

The program IBM SPSS Statistics 20 (IBM Corporation, New York, USA) was used for calculation of means, standard deviations and medians, and the program STATA 12 (StataCorp LP, College Station, Texas, USA) was used for statistical analysis of the data. Data were tested for normality using the Wilk-Shapiro test. A P value $\leq 0.05$ was considered significant. The Bonferroni test was applied where appropriate.

\section{Approval of the study by an ethical committe}

The study was approved by an ethical committee of the canton of Zurich, Switzerland.

\section{Results}

\section{Clinical findings and parturition}

The detailed results of the clinical examinations were reported elsewhere [18]. In group A, the rectal temperature ranged from 38.2 to $39.0^{\circ} \mathrm{C}$ (mean $\pm \mathrm{sd}=38.6 \pm 0.26^{\circ} \mathrm{C}$ ), the heart rate was 68 to 84 beats per minute $(74.4 \pm$ $5.06 \mathrm{bpm})$ and the respiratory rate was 20 to 36 breaths per minute ( $28.8 \pm 5.27$ breaths per min). In group B, the rectal temperature ranged from 38.1 to $39.1^{\circ} \mathrm{C}$ (38.5 \pm $0.36^{\circ} \mathrm{C}$ ), the heart rate from 68 to 80 beats per minute $(74.2 \pm 3.53 \mathrm{bpm})$ and the respiratory rate from 24 to 32 breaths per minute $(28.0 \pm 2.83$ breaths per minute). In group B, parturition occurred without complications and there were no cows with retention of placenta. Milk production of cows in group B was 20 to 25 litres in the first 10 days post partum.

\section{Eating and rumination behaviour in control cows (group A)}

The mean duration of eating over the five-day period ranged from 275 to 319 minutes, the number of chewing cycles during eating from $18^{\prime} 236$ to $20^{\prime} 800$ and the number of eating phases from 16.3 to 18.2 per day (Table 1). There were no significant differences among days for the three variables. Based on these findings, the following reference intervals were established: duration of eating 212 to 394 minutes, number of chewing cycles $13^{\prime} 101$ to 26515 , number of eating phases 10 to 24 .

The mean duration of rumination over the five-day period ranged from 389 to 410 minutes, the number of regurgitated cuds from 481 to 508 , the number of chewing cycles per cud from 54 to 56 and the number of rumination phases from 12.9 to 13.8 per day (Table 1). There were no significant differences among days for these four variables. Based on these findings, the following reference intervals were established: duration of rumination 304 to 471 minutes, number of cuds 366 to 611, number of chewing cycles per cud 53 to 57 , number of rumination phases 9 to 18 .

\section{Eating and rumination behaviour in peripartum cows (group B)}

The duration of eating on the tenth day prepartum was 186 minutes per day, which was less than that of the control cows (Figure 1). It decreased to 114 minutes by the day of parturition, and then increased significantly

Table 1 Eating and rumination variables in 10 control cows (group A) during five consecutive days (mean \pm standard deviation or median, range in brackets)

\begin{tabular}{|c|c|c|c|c|c|c|}
\hline & & & Day & & & Reference interval $^{1}$ \\
\hline Variable & 1 & 2 & 3 & 4 & 5 & \\
\hline Duration of eating (min) & $292(261-372)$ & $319(269-382)$ & $275(230-376)$ & $282(222-426)$ & $319(240-361)$ & $212-394$ \\
\hline $\begin{array}{l}\text { Chewing cycles } \\
\text { during eating }\end{array}$ & $\begin{array}{l}19^{\prime} 134 \\
\left(16^{\prime} 299-31^{\prime} 609\right)\end{array}$ & $\begin{array}{l}20^{\prime} 209 \\
\left(17^{\prime} 015-24^{\prime} 437\right)\end{array}$ & $\begin{array}{l}19^{\prime} 284 \\
\left(15^{\prime} 033-28^{\prime} 177\right)\end{array}$ & $\begin{array}{l}18^{\prime} 236 \\
\left(13^{\prime} 683-28^{\prime} 178\right)\end{array}$ & $\begin{array}{l}20^{\prime} 800 \\
\left(14^{\prime} 662-23^{\prime} 014\right)\end{array}$ & $13^{\prime} 101-26^{\prime} 515$ \\
\hline Number of eating phases & $16.8 \pm 3.52(12-22)$ & $\begin{array}{l}17.9 \pm 3.35 \\
(13-21)\end{array}$ & $\begin{array}{l}16.3 \pm 3.77 \\
(12-22)\end{array}$ & $\begin{array}{l}16.9 \pm 3.96 \\
(11-22)\end{array}$ & $\begin{array}{l}18.2 \pm 3.62 \\
(13-24)\end{array}$ & $10-24$ \\
\hline $\begin{array}{l}\text { Duration of rumination } \\
\text { (min.) }\end{array}$ & $389(299-422)$ & $390(285-436)$ & $400(341-467)$ & $390(305-458)$ & $410(347-453)$ & $304-471$ \\
\hline $\begin{array}{l}\text { Number of regurgitated } \\
\text { cuds }\end{array}$ & $481(283-582)$ & $487(375-551)$ & $493(438-600)$ & $486(423-571)$ & $508(417-573)$ & $366-611$ \\
\hline Chewing cyles per cud & $54(40-77)$ & $54(43-73)$ & $56(40-71)$ & $54(39-73)$ & $54(40-73)$ & $53-57$ \\
\hline $\begin{array}{l}\text { Number of rumination } \\
\text { phases }\end{array}$ & $13.1 \pm 2.47(8-18)$ & $\begin{array}{l}13.3 \pm 2.21 \\
(12-19)\end{array}$ & $\begin{array}{l}13.8 \pm 2.10 \\
(12-19)\end{array}$ & $\begin{array}{l}13.4 \pm 2.37 \\
(11-19)\end{array}$ & $\begin{array}{l}12.9 \pm 2.47 \\
(10-19)\end{array}$ & $9-18$ \\
\hline
\end{tabular}

${ }^{1}$ Calculated from the data of the control cows (group A) collected during five days (see Methods). 


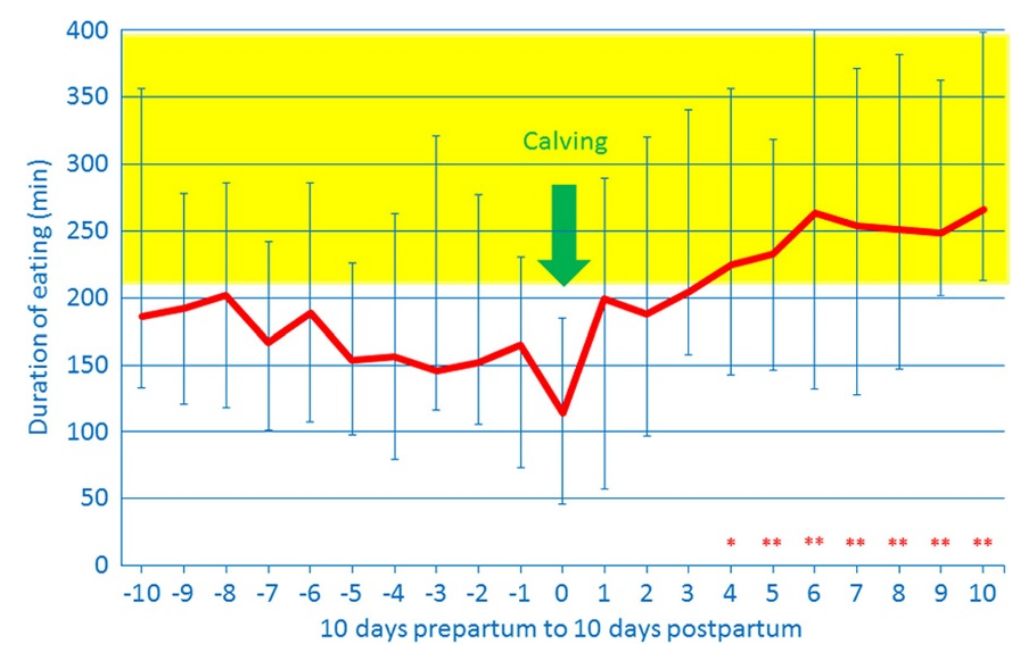

Figure 1 Duration of eating. Duration of eating in 10 cows (group B) from 10 days before to 10 days after parturition (medians, minimum, maximum). The yellow area indicates the reference interval (212 to $394 \mathrm{~min}$ ) calculated as the mean $\pm 2 \mathrm{sd}$ (302 $\pm 91.42 \mathrm{~min})$ of the recordings in 10 control cows (group A). * ${ }^{* *}$ compared with day 0 (parturition): $\mathrm{P}<0.05 / \mathrm{P}<0.01$ (Bonferroni test).

thereafter $(\mathrm{P}<0.01)$. By day 4 postpartum, the duration of eating had returned to the reference interval, and on day 10, it was 266 minutes, which was more than double the time recorded on day 0 .

The pattern recorded for the number of chewing cycles during eating was similar to that of the duration of eating (Figure 2). From day -10 to day -1 , the number of chewing cycles ranged from $13^{\prime} 347$ (day -8) to $8^{\prime} 971$ (day -3). The lowest number was recorded on the day of parturition $\left(7^{\prime} 008\right)$, which was followed by a significant increase $(\mathrm{P}<0.05)$. By day 3 postpartum, the count was within the reference interval. The number of chewing cycles increased to $15^{\prime} 931$ by day 10 postpartum, which was more than double the number recorded on the day of parturition.

The number of eating phases decreased slightly toward parturition from $16 \pm 1.4$ on day -10 to $14.9 \pm 3.37$ on day $0(\mathrm{P}>0.05)$ and then increased. The number was significantly higher on days $1(19.9 \pm 4.6)$ and $6(20.3 \pm 2.1)$ postpartum compared with the day of calving $(\mathrm{P}<0.05$ and $<0.01$ ).

The duration of rumination remained within the reference interval during the study except for the day of parturition (Figure 3). Before parturition, it ranged from 391 minutes (day -6) to 329 minutes (day -1), and on the day of parturition, it was significantly less at 214 minutes

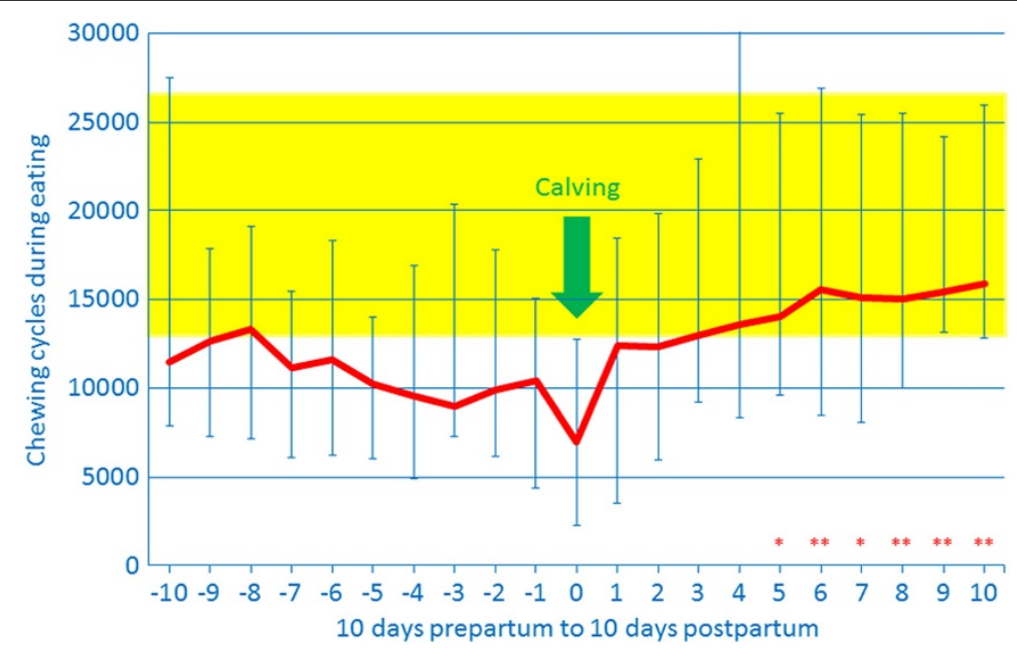

Figure 2 Number of chewing cycles during eating. Number of chewing cycles during eating in 10 cows (group B) from 10 days before to 10 days after parturition (medians, minimum, maximum). The yellow area indicates the reference interval (13'101 to $25^{\prime} 515$ chewing cycles) calculated as the mean $\pm 2 \mathrm{sd}\left(19^{\prime} 808 \pm 3^{\prime} 353.5\right.$ chewing cycles) of the recordings in 10 control cows (group A). *** compared with day 0 (parturition): $P<0.05 / P<0.01$ (Bonferroni test). 


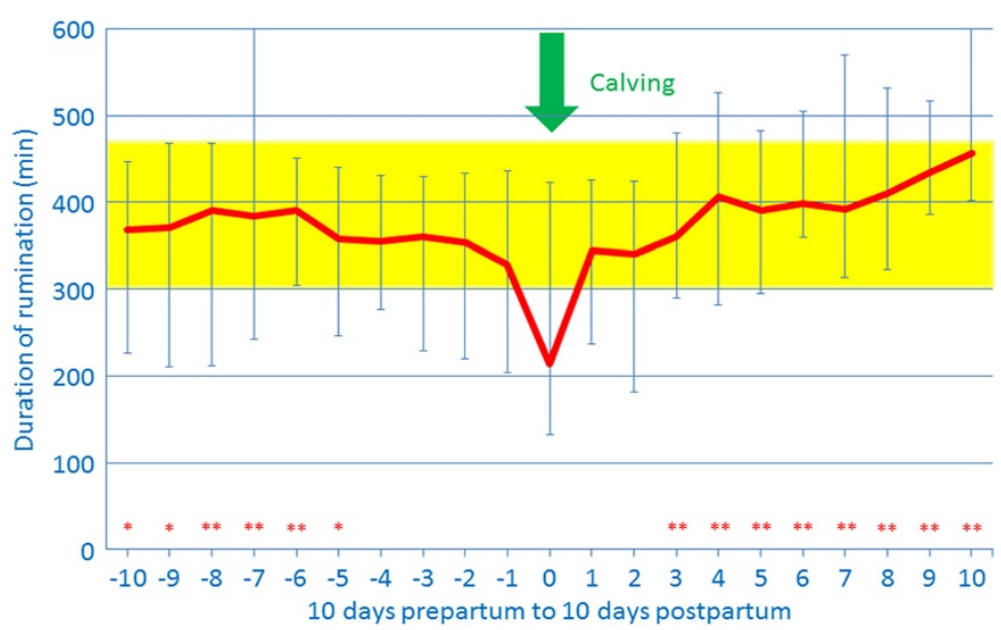

Figure 3 Duration of rumination. Duration of rumination in 10 cows (group B) from 10 days before to 10 days after parturition (medians, minimum, maximum). The yellow area indicates the reference interval (304 to $471 \mathrm{~min}$ ) calculated as the mean $\pm 2 \mathrm{sd}$ (387.8 $\pm 83.64 \mathrm{mi}$ ) of the recordings in 10 control cows (group A). ${ }^{* * *}$ compared with day 0 (parturition): $\mathrm{P}<0.05 / \mathrm{P}<0.01$ (Bonferroni test).

$(\mathrm{P}<0.05$ and 0.01$)$. It returned to the reference range by day 1 postpartum and increased to 457 minutes by day 10 (difference compared with day $0, \mathrm{P}<0.01$ ), which was more than double the time recorded on day 0 .

The number of regurgitated cuds per day was within the reference interval with the exception of day 0 (Figure 4). During the 10 days prepartum it ranged from 498 (day -8) to 440 (day -4). The number of cuds was lowest on day 0 with 362, just below the reference interval, and then increased significantly to 501 cuds by day $10(\mathrm{P}<0.01)$.

The number of chewing cycles per cud was below the reference interval on 12 of the 21 days of the study (Figure 5). The lowest number occurred on days -1 and 0 (45 cycles) and the largest number on day 9 (61 cycles).
The number of rumination phases did not change significantly during the study period and ranged from 12.2 on day 0 to 15.9 on day -3 .

\section{Discussion}

The duration of eating was reduced from the reference interval (212 to 395 minutes) to 186 minutes as early as ten days before parturition. Other authors determined reference intervals of 4 to 7 hours [5], 4 to 9 hours [1] and 4 to 12 hours [3]. The shortened eating time ten days before calving was in agreement with previous reports [8,11]; in the latter study, cows spent $35 \%$ less time at the feed alley starting as early as 2 weeks prepartum [11]. Cows approaching parturition eat more slowly than

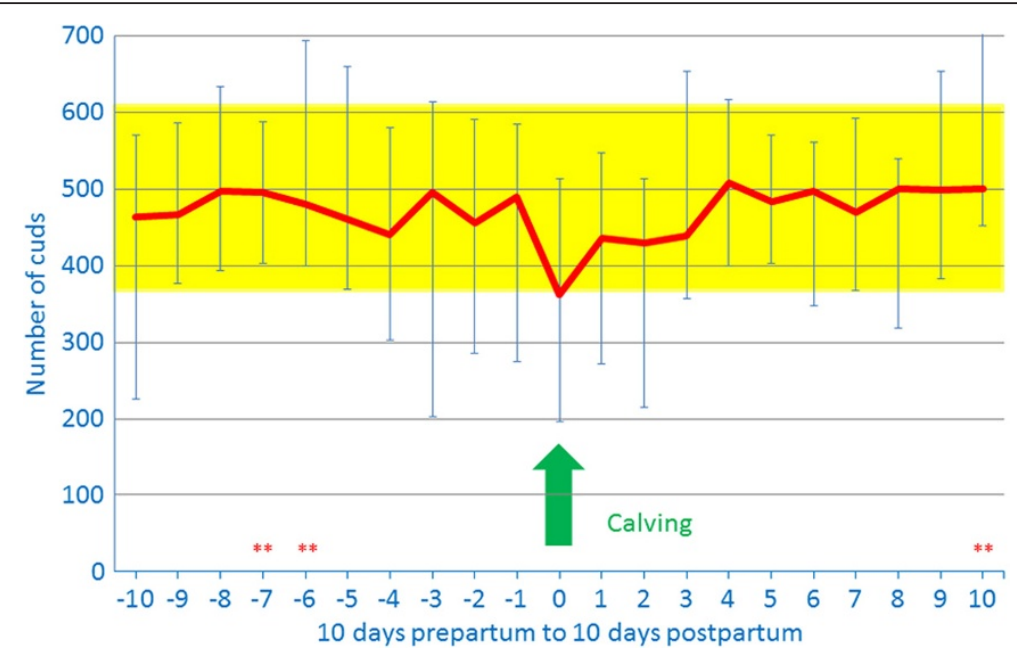

Figure 4 Number of regurgitated cuds. Number of regurgitated cuds in 10 cows (group B) from 10 days before to 10 days after parturition (medians, minimum, maximum). The yellow area indicates the reference interval (366 to 611 cuds) calculated as the mean $\pm 2 \mathrm{sd}$ (488.1 \pm 122.56 cuds) of the recordings in 10 control cows (group A). ${ }^{* *}$ compared with day 0 (parturition): $P<0.01$ (Bonferroni test). 


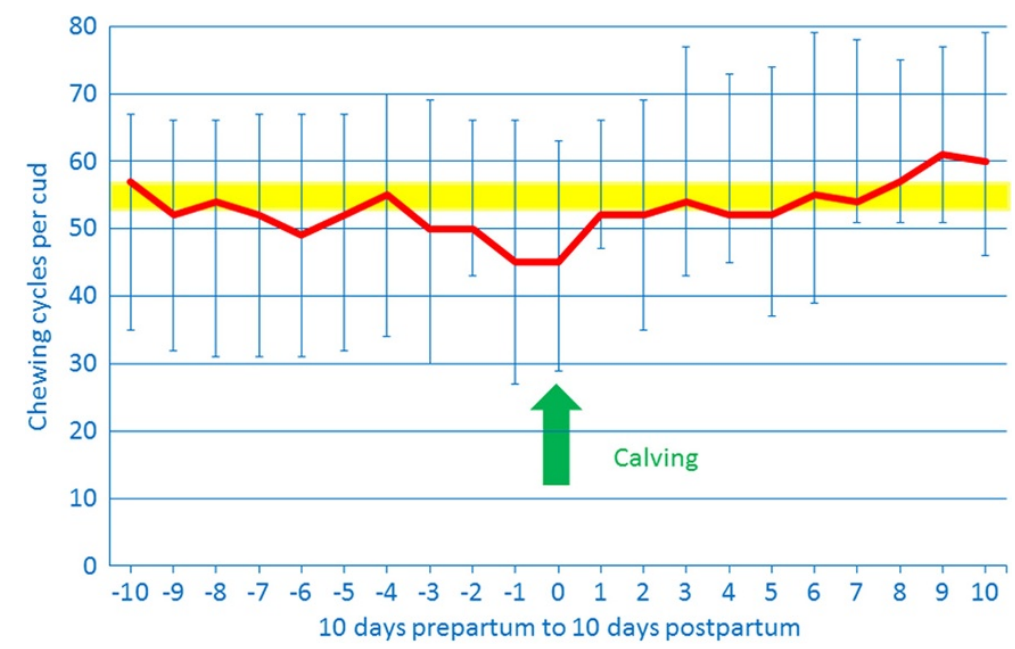

Figure 5 Number of chewing cycles per regurgitated cud. Number of chewing cycles per regurgitated cud in 10 cows (group B) from 10 days before to 10 days after parturition (medians, minimum, maximum). The yellow area indicates the reference interval (53 to 57 chewing cycles) calculated as the $90 \%$ confidence interval of the median of the recordings in 10 control cows (group A). *** compared with day 0 (parturition): $\mathrm{P}<0.05 / \mathrm{P}<0.01$ (Bonferroni test).

nonpregnant cows $[13,14]$, and combined with a shortened duration of eating, this is likely to reduce the overall feed intake. In the present study, eating time reached a minimum of 114 min on the day of calving but increased thereafter, and four days later, was in the reference interval of the control cows and the intervals established by other authors [5,19-21]. A progressive decrease in eating time in the last 10 days of pregnancy followed by resurgence two to three days later in cows was also described by others [8,12].

The patterns observed for the number of chewing cycles during eating and for the duration of eating were similar; they were below the reference interval ten days prepartum and then decreased further, most likely because of reduced eating time. The number of chewing cycles during eating and eating time increased simultaneously after parturition and by day 4 were in the normal range. Duration of eating and number of chewing cycles on day 10 were more than twice the values recorded on day 0 .

The duration of rumination in pregnant cows was within our calculated reference interval of 304 to $471 \mathrm{mi}-$ nutes (5.1 to 7.9 hours) throughout the study with the exception of day 0 . Our reference interval was within the 4 to 9 hour reference interval established by others $[1-3,5,19]$. However, the mean duration of rumination before parturition was consistently below 400 minutes, but rose quickly thereafter and was $>400$ minutes on day 4 and $>450$ minutes on day 10 . Reduced rumination time was probably attributable to the shortened eating time and smaller amount of ingesta available for rumination. Parturition is a stressful event that likely reduces the duration of rumination; a similar reduction was recorded in another study using the Hi-Tag Rumination
Monitoring System [15]. It is surprising that rumination time was not reduced more considering that rumination is hindered by excitement and stress [22] and requires a minimum level of wellbeing [23].

The number of regurgitated cuds in pregnant cows was within our calculated reference interval of 366 to 611 cuds per day with the exception of day 0 , when the number of cuds was 362. In another study, the number of cuds on the day of parturition was 360 to 790 [1], which was in agreement with our findings. Interestingly, the number of cuds after calving was within our calculated reference interval for the prepartum period, although duration of rumination per day increased by about 50 minutes between day 4 and day 10 .

The mean number of chewing cycles per regurgitated cud varied little in control cows and remained at 53 to 57 throughout the study. In group B, the range of 45 to 61 was larger, but still within the published reference interval of 40 to 70 chewing cycles per cud [24]. Analogous to other eating and rumination variables, the number of chewing cycles per cud was lowest on days -1 and 0 , indicating that not only the duration of rumination, but also the number of chewing cycles per cud appear to be subject to the cow's wellbeing [23], and that these variables were affected by labour. Limited feed intake and rumen fill most likely provided less stimulation of rumination $[5,23]$ and affected duration of rumination as well as number of chewing cycles. The number of chewing cycles per ruminated cud increased after calving with increasing feed intake parallel to the duration of rumination.

One limitation of the study was that the control group and group B did not receive the exact same diet. However, the majority of the diet in both groups consisted of 
hay offered ad libitum, and a direct comparison between the two groups was not made. The main purpose of the control group was to establish reference intervals, whereas the purpose of group B was to investigate eating and rumination behaviour from day 10 ante partum to day 10 post partum within the group and not primarily for comparison of results between groups. The diet of group B also changed post partum when corn silage and sugar beet pulp were fed. Feeding a high-energy ration post partum is vital for meeting the increased energy and protein demands for milk production in dairy cows [12]. Stimulation of appetite by offering fresh feed has been shown to increase feed intake and rumination variables post partum [3].

The question arises whether the reference intervals derived from 10 cows were representative considering the large variation among individuals. We therefore carried out another study [25] using 300 cows (100 BrownSwiss, 100 Simmental and 100 Holstein-Friesian cows) to establish reference intervals and the results were in agreement with those of the present study. We felt that it was important to obtain reference intervals during the same time period and to have the same person carry out the measurements using the same methods in both groups.

It was stated in the Introduction that "Identifying abnormal eating and rumination behaviour during the peripartum period may aid in diagnosing cows with subclinical disease, thereby allowing prompt treatment". The reference intervals established in our study provide only a rough assessment of eating and rumination behaviour. It is plausible that reference intervals would need to be established for each herd because eating and rumination behaviour would be affected by feeding, milk production and many other factors that vary from farm to farm. Nevertheless, our study showed that eating and rumination behaviour decrease before parturition and increase afterwards. The halter could be used to monitor these behaviours in individual cows on individual farms. A normal finding is that the variables decrease and then increase again. Daily monitoring of fluctuations could indicate abnormal changes such as a lack of increase in eating and rumination behaviour post partum or sudden stagnation. Automated programs will soon be available that alert the farm manager to changes of $20 \%$ or more, which would then prompt further evaluation of the cow.

\section{Conclusions}

The duration of eating and the number of chewing cycles during eating in pregnant cows progressively decreased up to and including the day of parturition and then rose sharply afterwards. In contrast, the duration of rumination and the number of regurgitated cuds were reduced only on the day of parturition. This was followed by a marked increase in duration of rumination by four days postpartum compared with the prepartum level.

\section{Competing interests}

The authors declare that they have no competing interests.

\section{Authors' contributions}

UB initiated, planned and supervised the study, and he wrote the manuscript, TS performed the study and MH did the statistical evaluation. All authors have read and approved the manuscript.

\section{Acknowledgements}

The authors thank the animal assistants for looking after the cows, Alois and Michael Bless for the cows and Dr. Chris Winder Waelchli for translating the manuscript. This study was financed by the University of Zurich, Switzerland

Received: 1 April 2014 Accepted: 15 August 2014

Published: 4 September 2014

\section{References}

1. Gürtler H: Physiologie der Verdauung und Absorption. In Lehrbuch der Physiologie der Haustiere. Edited by Kolb E. Jena: Gustav Fischer Verlag; 1974.

2. Hill H: Die Verdauung. In Lehrbuch der Veterinär-Physiologi. Edited by Scheunert A, Trautmann A. Berlin, Hamburg: Paul Parey; 1976:93-187.

3. Dulphy JP, Remond B, Theriez M: Ingestive behaviour and related activities in ruminants. In Digestive Physiology and Metabolism in Ruminants. Edited by Ruckebusch Y, Thivend P. Lancaster: MTP Press; 1980:103-123.

4. Welch JG, Hooper AP: Ingestion of feed and water. In The Ruminant Animal: Digestive Physiology and Nutrition. Edited by Church DC. Englewood C. New Jersey: Prentice Hall; 1988:108-117.

5. Beauchemin KA: Ingestion and mastication of feed by dairy cattle. Vet Clin North Am Food Anim Pract 1991, 7:439-463.

6. Trösch L: Untersuchungen über das Fressen und Wiederkauen von Kühen mit Hilfe eines Drucksensors im Halfter, Dr Med Vet Thesis. Zurich: University of Zurich; 2013

7. Braun U, Trösch L, Nydegger F, Hässig M: Evaluation of eating and rumination behaviour in cows using a noseband pressure sensor. BMC Vet Res 2013, 9:164

8. Journet $M$, Remond B: Physiological factors affecting the voluntary intake of feed by cows: a review. Livest Prod Sci 1976, 3:129-146.

9. Goff JP, Horst RL: Physiological changes at parturition and their relationship to metabolic disorders. J Dairy Sci 1997, 80:1260-1268.

10. Green DA, Brink DR, Bauer ML: Characterization of feed intake and estradiol-17 $\beta$ during gestation and lactation in twin-bearing ewes. Small Ruminant Res 1994, 13:153-158.

11. Urton G, Von Keyserlingk MAG, Weary DM: Feeding behavior identifies dairy cows at risk for metritis. J Dairy Sci 2005, 88:2843-2849.

12. Allen MS, Bradford BJ, Harvatine KJ: The cow as a model to study food intake regulation. Annu Rev Nutr 2005, 25:523-547.

13. Campling RC: A preliminary study of the effect of pregnancy and of lactation on the voluntary intake of food by cows. Br J Nutr 1966, 20:25-39.

14. Das KS, Das N: Feeding behavior of pregnant dairy heifers during last trimester under loose housing system. Asian-Aust J Anim Sci 2007, 20:1402-1406.

15. Soriani N, Trevisi E, Calamari L: Relationships between rumination time, metabolic conditions, and health status in dairy cows during the transition period. J Anim Sci 2012, 90:4544-4554.

16. Nydegger F, Gygax L, Egli W: Automatisches Messen der Kaubewegungen bei Wiederkäuern mit Hilfe eines Drucksensors. Agrarforschung Schweiz 2011, 2(2):60-65.

17. Rosenberger G: Die klinische Untersuchung des Rindes. 3rd edition. Berlin: Hamburg, Paul Parey; 1990.

18. Tschoner T: Untersuchungen über das Fressen und Wiederkauen bei kranken Kühen und bei Kühen um den Zeitpunkt der Geburt, Dr Med Vet Thesis. Zurich: University of Zurich; 2013.

19. Krause KM, Combs DK, Beauchemin KA: Effects of forage particle size and grain fermentability in midlactation cows. II. Ruminal pH and chewing activity. J Dairy Sci 2002, 85:1947-1957. 
20. Azizi O, Hasselmann L, Kaufmann O: Variations in feeding behaviour of high-yielding dairy cows in relation to parity during early to peak lactation. Arch Tierz 2010, 53:130-140.

21. Gomez A, Cook NB: Time budgets of lactating dairy cattle in commercial freestall herds. J Dairy Sci 2010, 93:5772-5781.

22. Herskin MS, Munksgaard L, Ladewig J: Effects of acute stressors on nociception, adrenocortical responses and behavior of dairy cows. Physiol Behav 2004, 83:411-420.

23. Kaske M: Vormagenmotorik und Ingestapassage. In Physiologie der Haustiere. Edited by Engelhardt WV, Breves G. Stuttgart: Enke Verlag; 2005:326-337.

24. Porzig E, Sambraus HH: Nahrungsaufnahmeverhalten landwirtschaftlicher Nutztiere. Berlin: Deutscher Landwirtschaftsverlag GmbH; 1991:31-146. 1991.

25. Zürcher S: Untersuchungen über das Fressen und Wiedekauen von Kühen verschiedener Rassen mit Hilfe eines Drucksensors im Halfter, Dr Med Vet Thesis. Zurich: University of Zurich; 2014.

doi:10.1186/s12917-014-0195-6

Cite this article as: Braun et al.: Evaluation of eating and rumination behaviour using a noseband pressure sensor in cows during the peripartum period. BMC Veterinary Research 2014 10:195.

\section{Submit your next manuscript to BioMed Central and take full advantage of:}

- Convenient online submission

- Thorough peer review

- No space constraints or color figure charges

- Immediate publication on acceptance

- Inclusion in PubMed, CAS, Scopus and Google Scholar

- Research which is freely available for redistribution 